\title{
Stress Corrosion Cracking in 316L Stainless Steel Bellows of a Pressure Safety Valve
}

\author{
Bijayani Panda, M. Sujata, M. Madan, S.K. Bhaumik \\ Council of Scientific and Industrial Research (CSIR), National Aerospace Laboratories, \\ Materials Science Division, Bangalore 560 017, INDIA
}

\begin{abstract}
There were three consecutive occurrences of bellows failure in a particular pressure safety valve (PSV) of a petroleum refinery within a time span of one week. The bellows were made of $316 \mathrm{~L}$ grade austenitic stainless steel, and the PSV was mounted on one of the vessels of vacuum gas oil service in a hydrocracker unit. Metallurgical analysis of the failed bellows revealed that the failure had occurred by stress corrosion cracking (SCC). It was found that the SCC was promoted in the bellows due to presence of high amount of chloride ions in the operating environment. Studies confirmed that SCC had initiated from the outer surface of the bellows and propagated inwards, resulting in leakage of hydrocarbon from the PSV. The source of chlorine in the environment was identified. It was discovered that SCC in the bellows was caused due to a previous failure in the heavy polynuclear aromatics (HPNA) absorption bed located upstream the process flow line. This failure was due to presence of high concentrations of chlorine in the granulated activated carbon that was used in the HPNA absorption bed. During the repair of the HPNA bed, there was deposition of carbon soot on the body of the PSV. This carbon soot was the source of chloride ions for SCC to occur in the bellows. Generally, in chloride SCC, crack propagation in $316 \mathrm{~L}$ SS takes place by transgranular mode. In the present case, however, the crack propagation was predominantly by intergranular mode. The metallurgical factors responsible for this change in micro-mechanism of crack propagation during SCC have been discussed.
\end{abstract}

Keywords: 316L stainless steel bellows; hydrocracker unit; pressure safety valve; chloride SCC; intergranular cracking

\section{Introduction}

Stress corrosion cracking (SCC) is a mechanical-environmental failure process in which sustained tensile stress well below the yield stress of the material and chemical attack combine to initiate and propagate fracture in metallic parts. SCC is often difficult to detect prior to component fracture, since the failure takes the form of fine cracks that penetrate deep into the component with little or no evidence of corrosion on the external surface. In failures involving SCC, the crack initiation and propagation may respond in different ways in different environments. While the crack initiation depends 
on the bulk environment, the crack propagation depends on the crack-tip environment and the microstructural constituents in the material. Generally, SCC takes place by extensive branching and proceeds in a direction perpendicular to the direction of stresses contributing to their initiation and propagation [1]. Crack initiation occurs due to localized electrochemical dissolution of the metal. The protective films that form at the crack tip get ruptured with sustained tensile stresses, resulting in exposure of fresh anodic metal to the corrosive medium continuously and hence, the SCC propagates progressively over a period of time.

Bellows expansion joints manufactured from austenitic stainless steels are extensively used for various applications in space and nuclear industries [2$6]$. These are often used in systems that are exposed to liquid fuel and propellant $[2,6]$. Other applications of bellows include heating systems of steam and water in petrochemical industries. Under the application environment, the bellows are subjected to both mechanical stresses and corrosion environment, and hence, are prone to failures due to progressive damage. Fatigue, corrosion fatigue, and SCC are common mechanisms of failures of bellows manufactured from austenitic grade stainless steels [2-4]. The present paper discusses recurring failure of bellows made of AISI $316 \mathrm{~L}$ grade stainless steel. The bellows, manufactured from a double ply sheet of thickness $0.2 \mathrm{~mm}$, was installed in a pressure safety valve (PSV) of a hydrocracker unit in a petroleum refinery plant.

\section{The Failure}

There was a series of failure of bellows installed in a PSV of a hydrocracker unit leading to leakage of process fluid. The first failure of the bellows took place after 13 years of service. After the first failure, the bellows was replaced by a new one. However, the failure continued to occur and in total, there were three consecutive failures in a span of one week duration. On-site inspection showed several cracks on the outer surface of the bellows. The operating pressure and temperature of the PSV were $1.6 \mathrm{~kg} / \mathrm{cm}^{2}$ and $100^{\circ} \mathrm{C}$ respectively. The construction of the PSV is illustrated schematically in Fig.1.

\section{Laboratory Investigation}

\subsection{Macroscopic examination}

Figure 2(a) shows the photograph of one of the cracked bellows. On observation under stereo-binocular microscope, several cracks were detected 
on the external surface of the bellows (Fig.2(b)). The cracks were located on the convolution crest and were oriented along the bellows axis. There were no cracks at the convolution root regions.

Suitable cut was made in the bellows and the two plies of the bellows were separated out. Examination showed presence of cracks in the inner ply as well. In this case also, the cracks were located at the convolution crest and not at the convolution root. The population of cracks in the inner ply was, however, several times less than that in the outer ply.

The bellows used in the PSV was of ' $\mathrm{S}$ '-type and the construction is shown schematically in Fig.3. The orientation of the cracks on the convolution crest is also shown. In as-received condition, the bellows surface was found to be clean and shiny in appearance. There were no external deposition or corrosion products on the surface. It was learnt that the bellows was cleaned prior to dispatch to the laboratory for investigation.

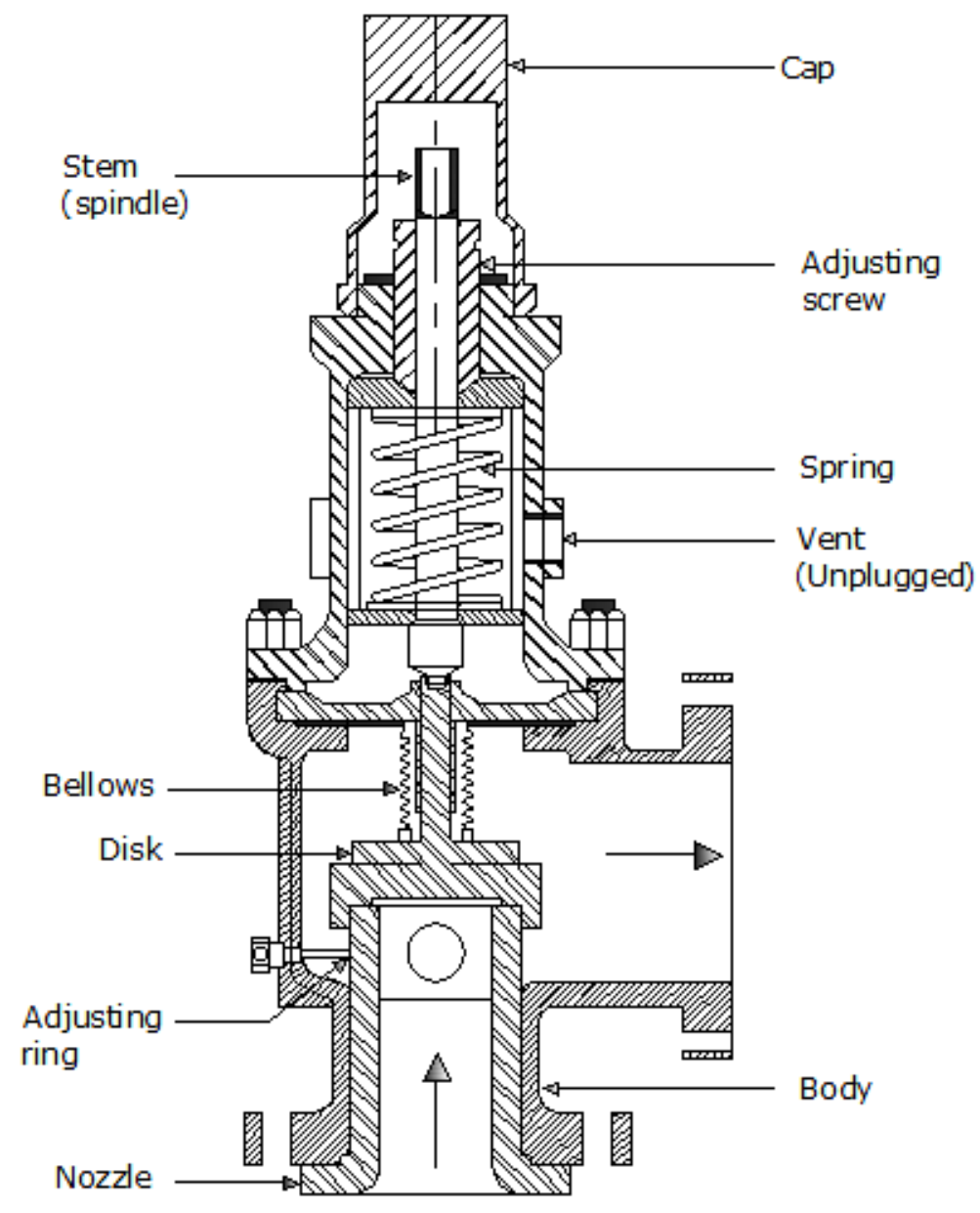

Figure 1 Schematic showing the bellows in the pressure safety valve (PSV) assembly 


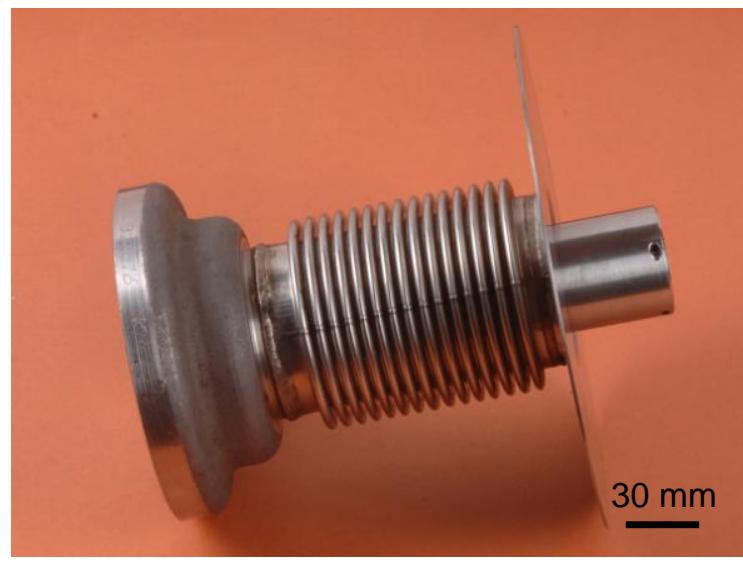

(a)

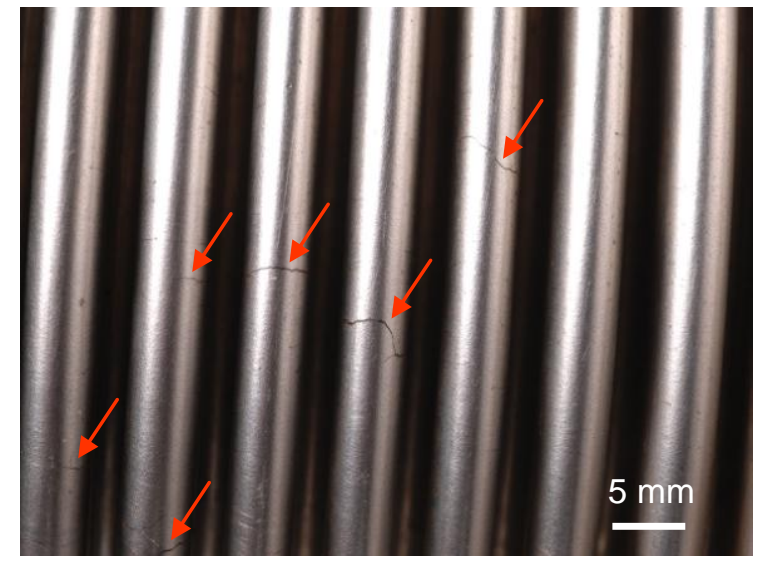

(b)

Figure 2 (a) Failed bellows, and (b) close-up view showing cracks (arrows) on the convolution crest regions

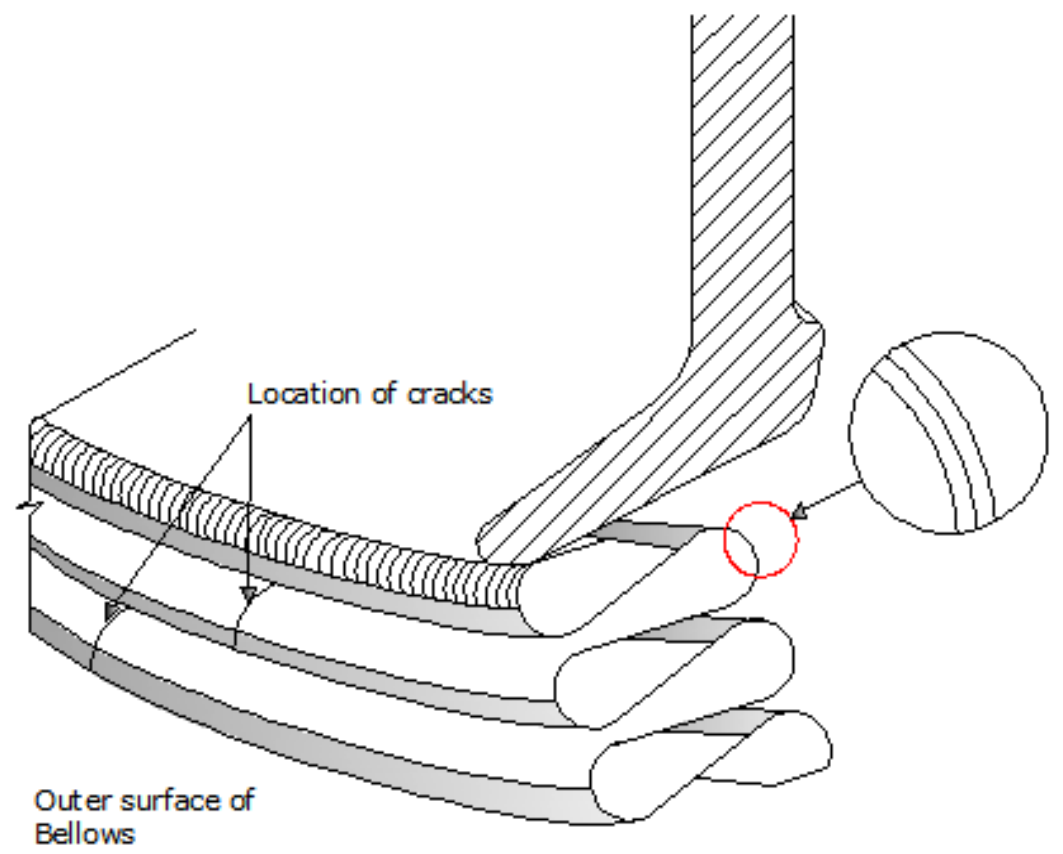

Figure 3 Schematic diagram showing construction of the bellows and the location of cracks on the bellows surface

\subsection{Mode of crack propagation}

A few cracks were pulled open for scanning electron fractographic study. Figure 4(a) shows an opened surface of one of the cracks on the outer ply of the bellows. It can be seen that the cracking of the bellows had occurred by intergranular mode of crack propagation (Fig.4(b)). Crack surface also showed presence of a number of secondary cracks in a direction perpendicular to the main crack surface. 


\subsection{Compositional analysis on crack surfaces}

Several locations on the crack surfaces were found covered with firmly adherent corrosion products (Fig.5). In-situ compositional analysis performed by energy dispersive X-ray (EDX) analyzer showed that the corrosion products contained chlorine and oxygen in significant concentrations in addition to the elements of the base material (Fig.6, Table 1). The concentration of chlorine in the corrosion products was determined to be as high as $6 \mathrm{wt} . \%$.

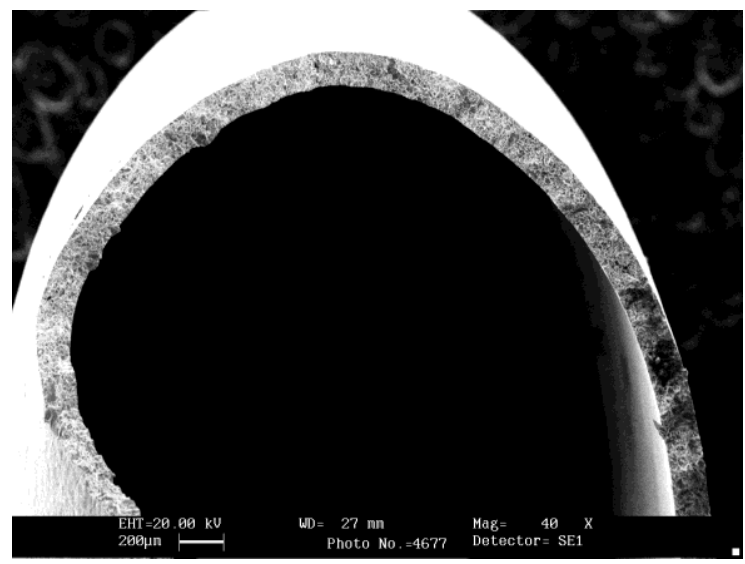

(a)

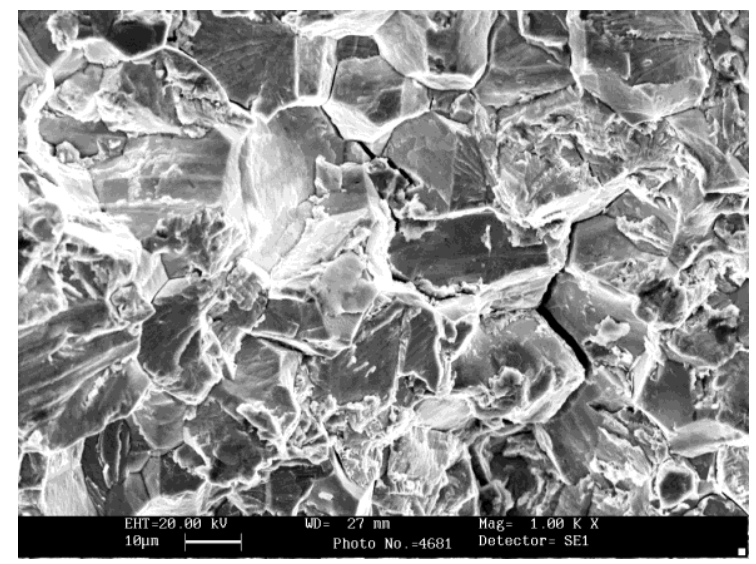

(b)

Figure 4 (a) Secondary electron image of a crack surface, and (b) intergranular mode of crack propagation with secondary cracks at the grain boundaries

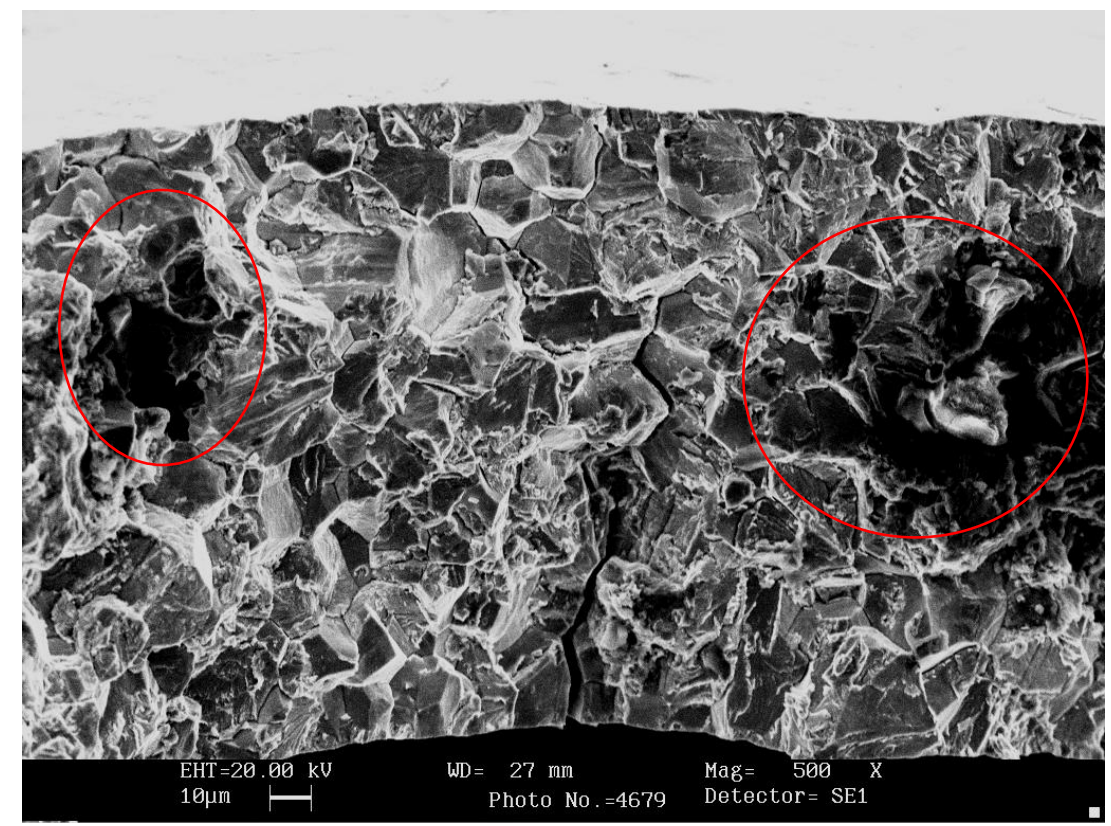

Figure 5 Secondary electron fractograph showing presence of firmly adherent corrosion products on the crack surface (encircled) 


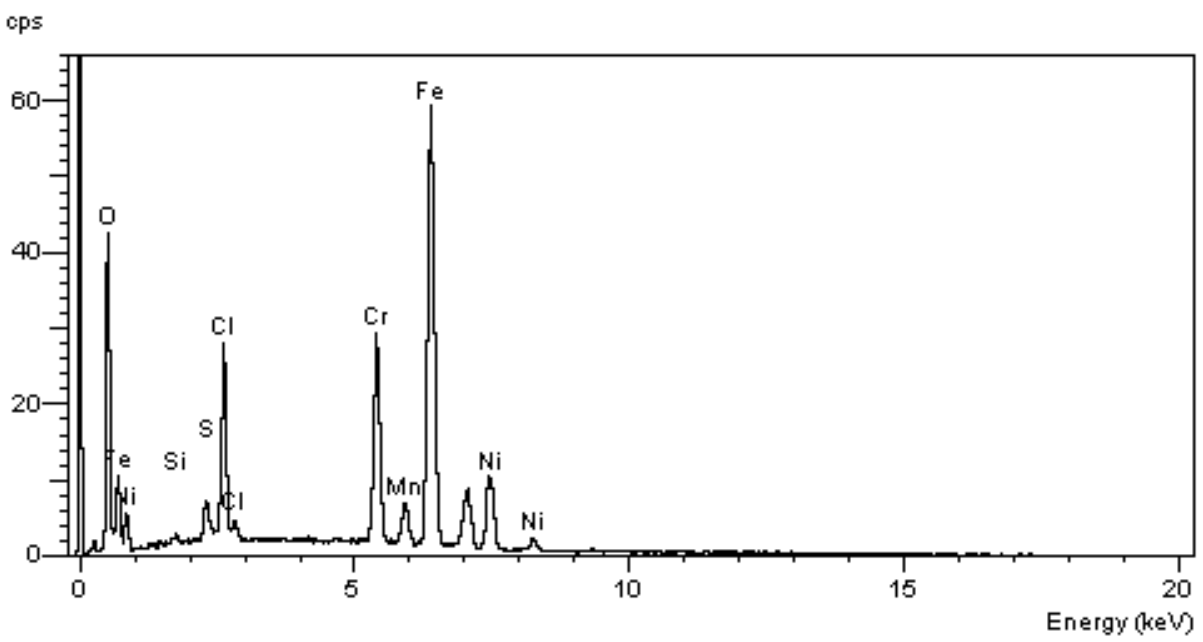

Figure 6 Energy dispersive X-ray spectrum of corrosion products on the fracture surface shown in Fig. 5

Table 1 Semi-quantitative compositional analysis of the bellows material and the corrosion products; carried out by energy dispersive X-ray (EDX) analysis

\begin{tabular}{|c|c|c|c|c|c|c|c|c|c|c|}
\hline \multirow[b]{2}{*}{ Element } & \multicolumn{10}{|c|}{ Composition, wt $\%$} \\
\hline & $C^{*}$ & $\mathrm{O}$ & $\mathrm{Si}$ & $\mathrm{S}$ & $\mathrm{Cl}$ & $\mathrm{Cr}$ & $\mathrm{Mn}$ & Mo & $\mathrm{Ni}$ & $\mathrm{Fe}$ \\
\hline $\begin{array}{l}316 \mathrm{~L} \\
\text { Specification }\end{array}$ & 0.03 & -- & 0.75 & -- & -- & $\begin{array}{c}16.0- \\
18.0\end{array}$ & 2.0 & $\begin{array}{l}2.0- \\
3.0\end{array}$ & $\begin{array}{c}10.0- \\
14.0\end{array}$ & Balance \\
\hline Bellows material & -- & -- & 0.6 & -- & -- & 17.8 & 1.7 & 2.4 & 11.0 & Balance \\
\hline $\begin{array}{l}\text { Corrosion } \\
\text { Products on the } \\
\text { fracture surface }\end{array}$ & -- & 23.6 & 0.2 & 0.7 & 5.9 & 12.7 & 1.4 & -- & 11.7 & Balance \\
\hline
\end{tabular}

* Carbon cannot be determined accurately by EDX analysis

\subsection{Metallographic examination}

A few samples containing cracks were cut from the plies of the bellows, mounted on the cross section along the transverse direction of the bellows and metallographically prepared. Figure 7 shows the cross section of the plies of the bellows in un-etched condition. A few through and propagating cracks in the outer ply of the bellows can be seen. Figure 8(a) shows a typical propagating branching crack initiating from the outer surface of the bellows. The origin of crack initiation was a tiny region of pitting corrosion on the outer surface. The magnified view of the cracked region is shown in Fig.8(b). Although the branching cracks are predominantly intergranular in nature, transgranular crack propagation can be seen at a few locations. 
Wherever the cracks are transgranular, they are found to be following the twin boundaries within the austenite grains of the sheet material.

Figure 9(a) shows a secondary electron image of the cross section of the inner ply in the vicinity of a through crack in the outer ply. Magnified view of the region is shown in Fig.9(b). Initiation of a number of cracks on the outer surface of the inner ply can be seen. At a few places, the cracks were found to have propagated through the thickness of both the plies of the bellows (Fig.10).

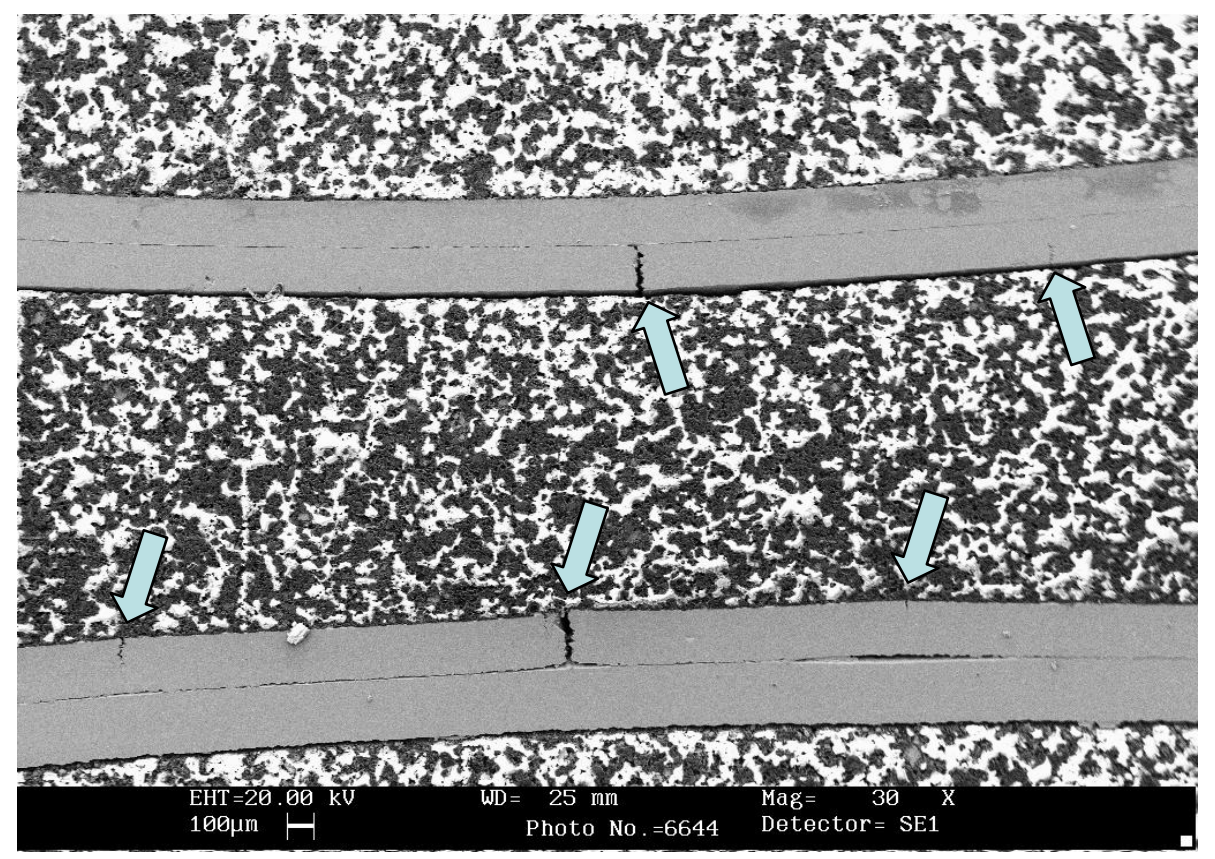

Figure 7 Secondary electron micrographs of two transverse sections of the bellows showing through cracks (arrows) in the outer ply

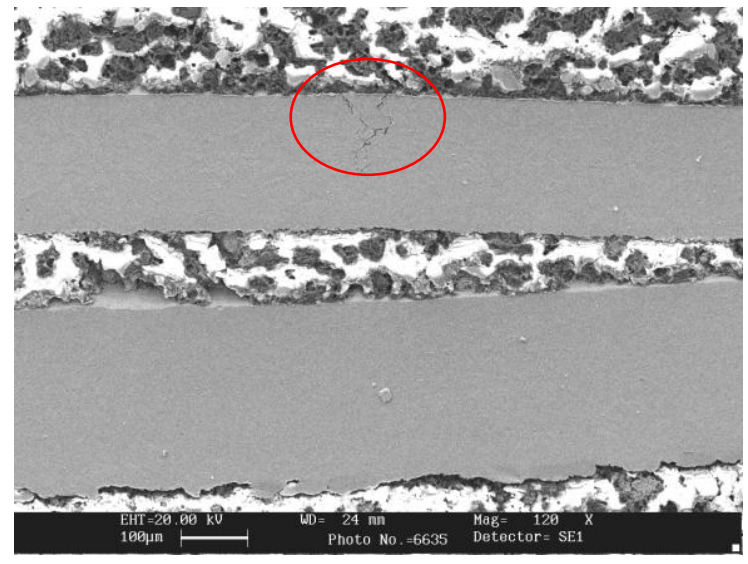

(a)

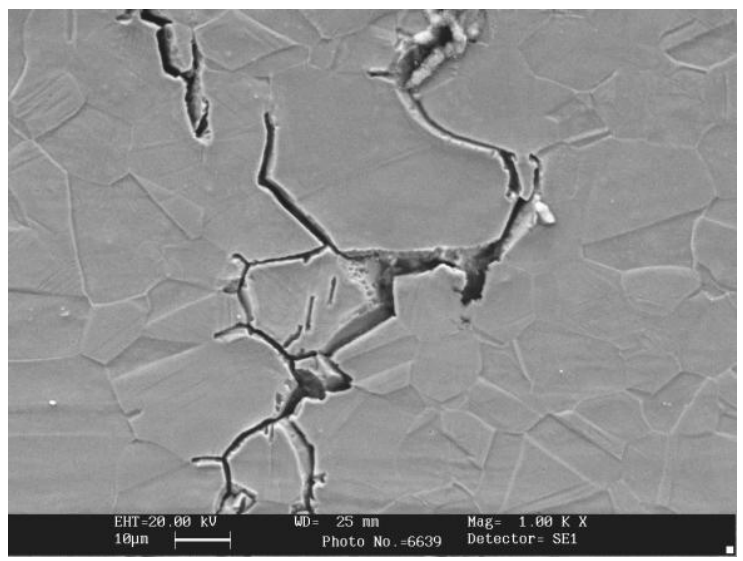

(b)

Figure 8 Secondary electron micrographs showing (a) crack initiation region (encircled) on the outer ply of the bellows, and (b) magnified view showing branching cracks 


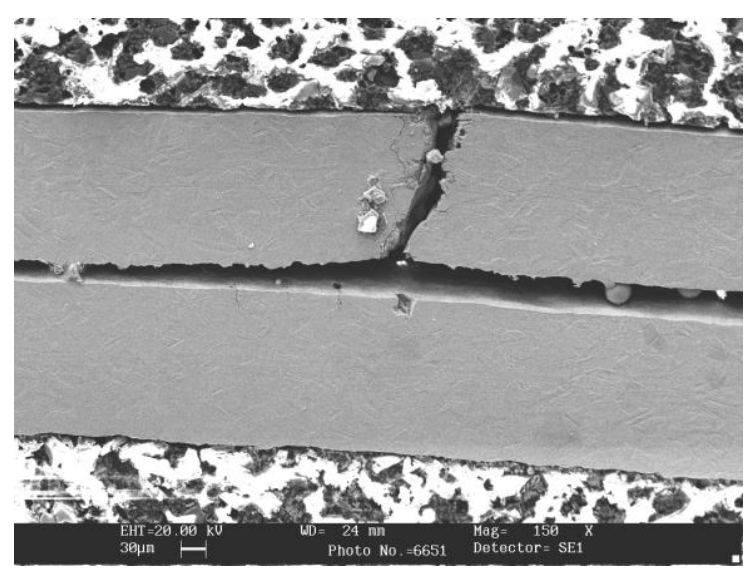

(a)

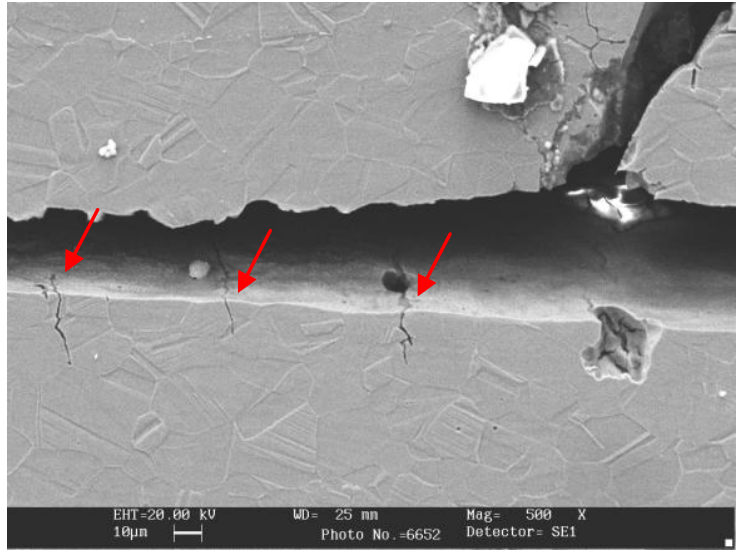

(b)

Figure 9 Secondary electron micrographs showing (a) a through crack in the outer ply of the bellows, and (b) cracks in the inner ply in the vicinity of the through crack in outer ply shown in (a)

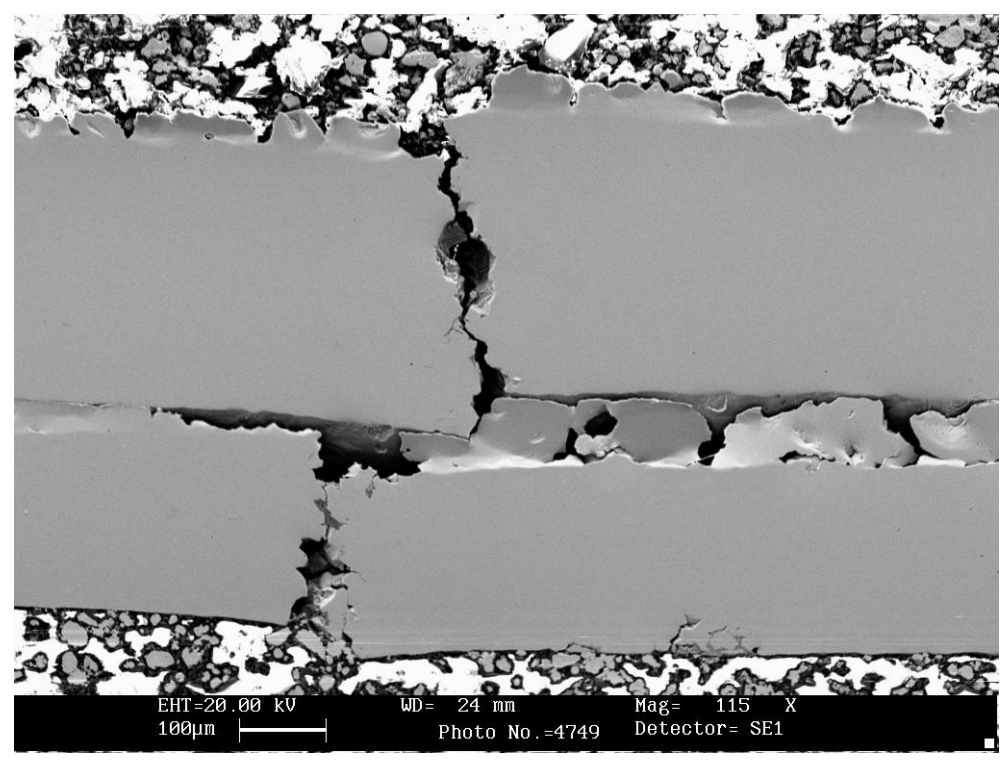

Figure 10 Secondary electron micrograph showing through thickness crack in both the plies of the bellows

\subsection{Analysis of bellows material}

Compositional analysis showed that the bellows was made of $316 \mathrm{~L}$ grade austenitic stainless steel and it conformed to the design specification (Table 1). The optical microstructures of the bellows material are shown in Fig.11. It consisted of austenite grains. There was no predominance of carbide precipitation at the grain boundaries, eliminating the possibility of sensitization of steel. Study, however, showed extensive formation of shear 
bands and deformation twins within the austenite grains (Fig.11(a)). Also, at the central region of the sheet cross section, the microstructure showed presence of stress induced martensite phase (Fig.11(b)).

Hardness of the bellows material was determined on longitudinal section of the bellows using Vickers micro-hardness tester at a load of $100 \mathrm{~g}$. The hardness values were found to be in the range 215 to $302 \mathrm{HV}$, confirming that the bellows was fabricated from cold rolled austenitic stainless steel sheet. Results of the hardness survey, however, showed that average hardness at the convolution crest was significantly higher than that at the convolution root as well as other locations of both the plies of the bellows (Fig.12).

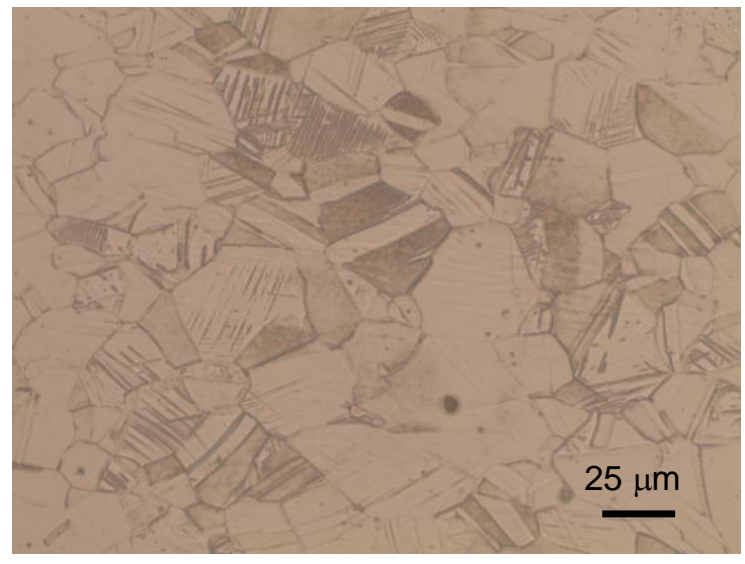

(a)

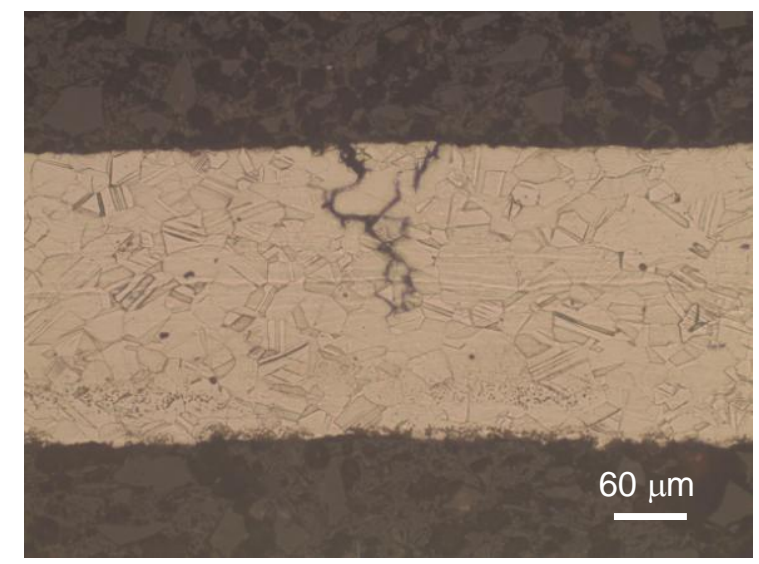

(b)

Figure 11 Optical micrographs showing (a) shear bands and twins within the austenite grains, and (b) stringers of stress induced martensite phase at the mid-section of the sheet

\section{Discussion}

Study showed that all three bellows failures in the PSV of the hydrocraker unit were identical in nature. There was severe cracking in both the plies of the bellows leading to leakage of the process fluid.

\subsection{Failure mechanism}

Fractographic and metallographic studies showed that the cracks in the plies of the bellows have propagated predominantly by intergranular mode, and they were branching in nature. In several places, the crack surfaces were covered with firmly adherent corrosion products. In-situ compositional 
analysis showed that the corrosion products contained chlorine in concentrations as high as $6 \mathrm{wt} \%$. The branching cracks in the bellows and presence of corrosion products on the fracture surface are characteristic of SCC. High concentration of chlorine in the corrosion products also indicates that the failure of the bellows was by chloride SCC.

Laboratory investigation confirmed that the stress corrosion cracks had initiated on the outer surface of the bellows. It is, therefore, apparent that the source of chloride ions was the environment surrounding the outer surface of the bellows. Once there were through cracks in the outer ply of the bellows, the inner ply was exposed to corroding media. It has been shown that the cracks in the inner ply had also initiated on the outer surface. When both the plies of the bellows developed through cracks, there was leakage of process fluid from the PSV.

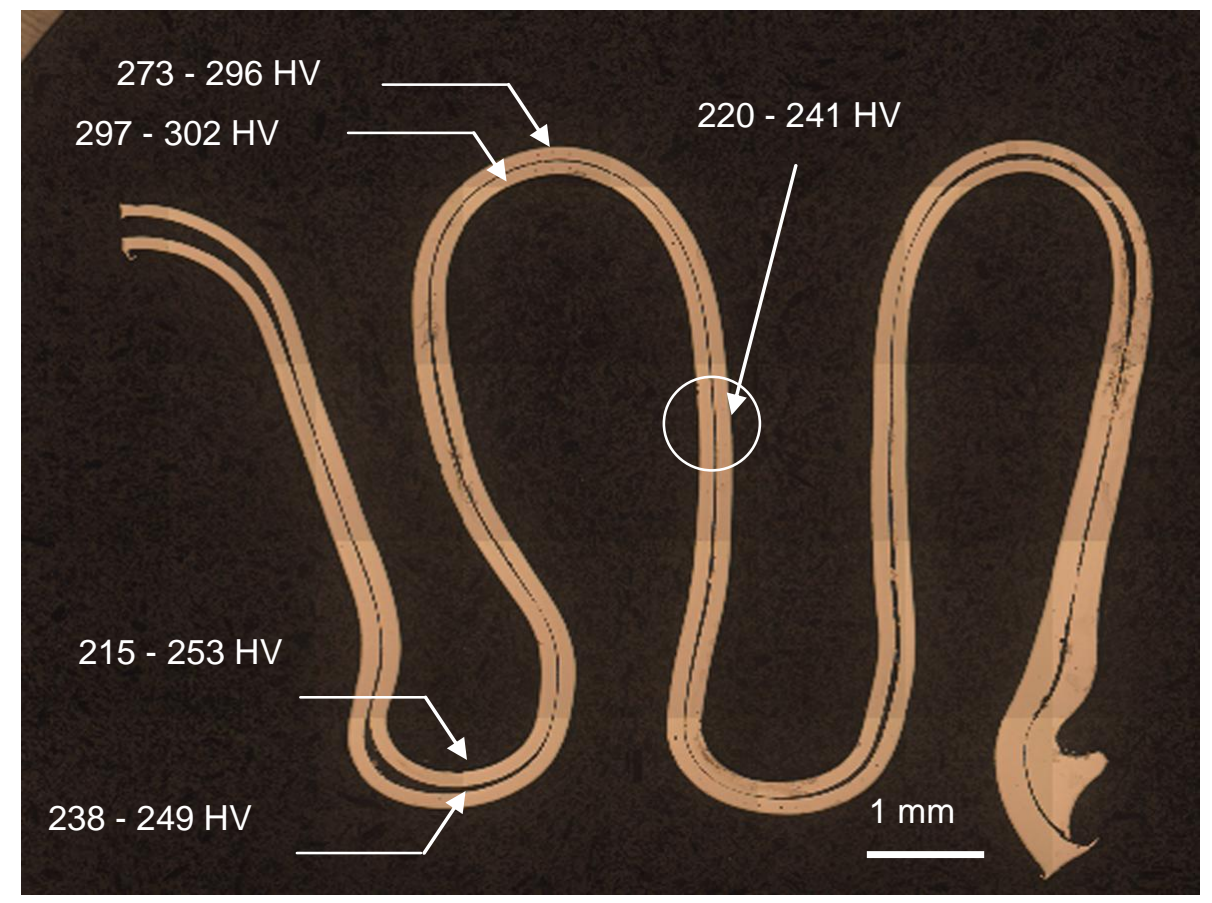

Figure 12 A montage of optical micrographs of the longitudinal section of a part of the bellows; note significantly higher hardness at the convolution crest relative to that at the convolution root

\subsection{Micro-mechanism of crack propagation}

Chloride SCC in austenitic stainless steel usually occurs only at temperatures above $70^{\circ} \mathrm{C}$ [1]. In the present case, the process fluid temperature is $100^{\circ} \mathrm{C}$ 
and hence, if chloride ions are present in the environment in sufficient concentration, chloride SCC in the bellows is likely to occur.

It is well known that in the presence of chloride ions, SCC in austenitic stainless steels proceeds in transgranular mode [1]. Scanning electron fractographic study, however, showed that in the case of present failure, the micro-mechanism of crack propagation was predominantly by intergranular mode. Although this is unusual, intergranular chloride SCC has been reported to occur in $316 \mathrm{~L}$ stainless steel under certain conditions. For example, during chloride SCC of austenitic stainless steel, crack propagation takes place by intergranular mode if the grain boundaries are anodic with respect to the grain bodies [1, 7-8]. This is commonly the case, when the material is sensitized. In sensitized steel, the precipitation of chromium carbide at the grain boundaries results in chromium depleted zones adjacent to the grain boundaries. The chromium depleted zones along the grain boundaries are anodic to the main body of the grains, and hence, SCC progresses intergranulary $[7,8]$. Microstructural study of the bellows material, however, did not show grain boundary carbide precipitation. Hence, inference can be drawn that the intergranular mode of crack propagation in the present case is because of reasons other than sensitization of steel.

In spite of the microstructure being not sensitized, intergranular mode of SCC can still occur in austenitic grades of stainless steel under certain specific conditions $[1,9,10]$. Intergranular SCC in austenitic stainless steels has been reported [1] in boiling-water nuclear reactors where the steels were free from grain-boundary carbides but they were used in heavily cold-worked condition. It is well known [9-11] that in 316L stainless steels, the austenite phase is not absolutely stable under stress. Plastic deformation can induce transformation of austenite to martensite phase. Presence of deformation induced martensite phase in the microstructure facilitates intergranular crack propagation during SCC in the following two ways $[9,10]$.

(a) Dissolution rate of martensite in corrosive environment is much higher than austenite, and hence, crack propagation occurs preferentially along the martensite phase.

(b) Martensite phase has high hydrogen diffusivity and low hydrogen solubility in comparison to austenite phase. Hence, presence of martensite phase in the microstructure induces hydrogen embrittlement and thereby, the crack propagation can occur by intergranular mode. The source of hydrogen is the in-situ generation of nascent hydrogen by electrochemical reaction that takes place during SCC. 
In general, cold worked sheet materials are used for fabrication of bellows. This is necessary to impart structural stiffness to the component. Cold working often introduces shear bands within the austenitic grains in concurrence with stress induced martensitic transformation in the material. Metallographic study confirmed that the sheet material used in the construction of the bellows was in cold worked condition and the microstructure contained shear bands as well as stress induced martensite phase. Hence, intergranular mode of crack propagation during chloride SCC in the present case is justifiable.

\subsection{Crack initiation at the convolution crest of the bellows}

It has been established through fractographic and metallographic studies that all cracks have initiated at the convolution crest. In none of the failed bellows studied, there was crack initiation at the convolution root irrespective of whether they are in outer or inner ply of the bellows.

Sitko and Skoczen [12] carried out finite element modeling studies on strain induced martensite formation in austenite grade stainless steel such as $316 \mathrm{~L}$ in different structural members. It has been shown that the propensity of strain induced martensite formation in the bellows is more at the bent regions, namely, convolution crest and root. Although the study was confined to a temperature of $77 \mathrm{~K}$, the results are applicable at ambient temperature as well.

Bellows expansion joints used in structural assemblies are subjected to thermal as well as mechanical stresses. The load-deflection characteristics are taken into consideration while designing the specific geometry of the bellows depending on the application [13]. In addition to satisfying the criterion for mechanical stresses, the resistance of the material to application corrosion environment is taken into account. Austenitic grade stainless steels meet these requirements and hence, are extensively used for applications such as nuclear power plant and petrochemical industries. Depending on the application, several categories of bellows such as universal, gimbal, hinged etc., are used. Similarly, varieties of convolution shapes such as ' $S$ ', ' $U$ ' ' $\Omega$ ' are used depending on the requirement, cost of manufacture etc. [14]. In the present case, the bellows used was of the ' $S$ ' type.

Bellows are manufactured from thin walled tubular section using roll forming or hydro-forming techniques. These methods of manufacture impart differential cold work at different regions of the bellows such as the convolution crest and the root. As a result, the strength of the material is 
locally changed and the resistance of the material to cyclic loading as well as corrosion attack varies from place to place. It has been reported [15] that with regard to fatigue, a combination of roll and hydro-forming is a better proposition for fabrication of bellows. In the same study, it has also been established that in hydro-formed bellows of austenitic grade stainless steels, the crest regions undergo more cold work compared to the root.

The results of the hardness survey conducted on the failed bellows showed substantially higher hardness at the convolution crest (273-302 HV) compared to that at other regions (215-253 HV). This indicates that probably, the manufacturing method followed resulted in large amount of cold work at the crests compared to elsewhere in the bellows. Since volume fraction of strain induced martensite is a function of amount of cold work, it is, therefore, natural that the martensite formation in the sheet material would be predominant at the convolution crest regions. In presence of corrosive environment, this would facilitate preferential crack initiation at the convolution crest as seen in the present case.

\subsection{Source of chloride ions}

The pipeline, on which the PSV was installed, was carrying hydrocarbon as the process fluid. This hydrocarbon was an unlikely source of chloride ions because (i) it was at the final stage of refining for the production of motor spirit, and (ii) its quality was being monitored regularly. Also, considering initiation of SCC on the outer surface of the bellows, it is apparent that the environment around the bellows was contaminated with chloride ions and not the hydrocarbon.

It is significant to note that the first failure of the bellows occurred after about 13 years of service of the PSV. Subsequently, there were two more failures of same kind in the same PSV in a span of one week. Three consecutive failures in such a short time are unexplainable unless there was a source of chloride ions in the system itself, which might have originated shortly before the first failure took place. Hence, the process and the operational history of the hydrocracker unit were examined in detail for identifying the probable source(s) of the chloride ions.

Figure 13 shows the process flow chart and associated equipment in the vicinity of the failed PSV. The PSV is mounted on the feed coalescer which discharges feedstock to the recycle splitter column. In another line and prior to the recycle splitter column, there is a system for removal of heavy polynuclear aromatics (HPNA) from the feedstock. The HPNA system consists 
of two beds filled with activated carbon. The HPNAs are adsorbed onto the activated carbon for increasing the downstream hydrocracker catalyst life and avoiding HPNA fouling of feed effluent heat exchangers. The outlet of the HPNA system also joins the splitter column. The outlet pipelines of the HPNA system and the PSV are interconnected. The pressures of both the systems, that is, feed coalescer discharge and the HPNA system are equal.

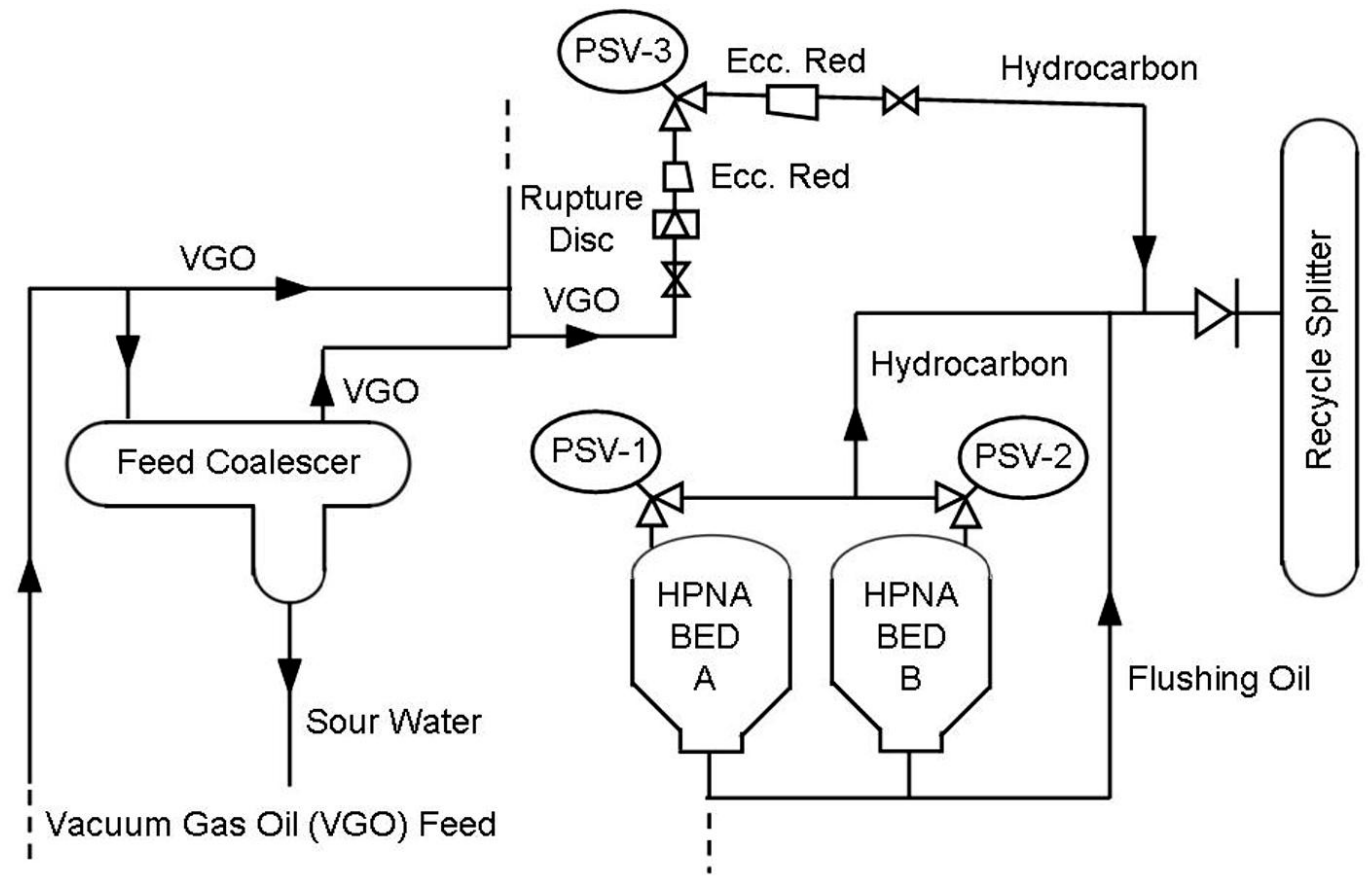

Figure 12 Schematic showing the process flowchart and the associated equipment in the vicinity of failed PSV-3

The HPNA bed contains granulated activated carbon which is supported by stainless steel screen. It was discovered that there was a failure in the HPNA bed prior to the first failure of the bellows. The failure was in the stainless steel screen. Laboratory tests revealed that this particular batch of activated carbon contained high amount of chlorine and this was responsible for the failure of the stainless steel screen by chloride SCC. The HPNA bed was repaired and the hydrocracker unit was re-commissioned. All the three bellows failures occurred after this incident.

Investigation revealed that subsequent to the failure of the bellows, when the PSV was dismantled for repair, its body was found covered with black deposit. The deposit was formed during the repairing of the HPNA bed and it consisted of activated carbon soot which contained chlorine in high concentration. It was confirmed that this deposit was the source of chloride 
ions in the system which resulted in a series of bellows failures in the PSV by chloride SCC.

\section{Conclusions}

The failure of bellows in the PSV installed in a hydrocracker unit of a petroleum refinery plant was investigated. Based on the studies conducted, the following conclusions were drawn.

(a) The stainless steel bellows had failed by SCC. The SCC was promoted due to presence of chloride ions in the environment. The micromechanism of crack propagation was predominantly intergranular in nature.

(b) Investigation revealed that there was a failure in the HPNA bed preceding the failures of the bellows in the PSV. The failure in the HPNA bed was due to presence of high concentrations of chlorine in the granulated activated carbon. During the repair of the HPNA bed, there was deposition of activated carbon soot on the body of the PSV. The deposited carbon soot contained chlorine and hence, acted as the source of chloride ions for SCC to occur in the bellows. The failure of the bellows continued till the system was cleaned and the source of chloride ions eliminated.

(c) The material of construction of bellows conformed to the specification of $316 \mathrm{~L}$ grade stainless steel. Also, there were no microstructural abnormalities arising from sensitization of the steel, which could be responsible for the failure of the bellows by SCC.

(d) The microstructural changes occurred during forming the bellows by hydro-forming method was responsible for initiation of SCC preferentially at the convolution crest. The presence of stress induced martensite phase in the microstructure of the formed sheet material influenced the micro-mechanism of crack propagation such that it was intergranular in nature.

\section{Acknowledgements}

The help received from M/s K. Raghavendra and S. Mallanna for fractographic study and metallographic sample preparation respectively is gratefully acknowledged. 


\section{References}

[1] Metals handbook. Stress corrosion cracking, vol. 10: Failure analysis and prevention, $8^{\text {th }}$ ed. American Society for Metals, 1975. p. 205-227.

[2] Y.Z. Zhu, H.F. Wang, Z.F. Sang, The effect of environmental medium on fatigue life for U-shaped bellows expansion joints, Int. J. Fatigue. 28 (2006) 28-32.

[3] N. Radek, S. Filippo, L. Debarberis, S. Petr and M. Kytka, Testing environmentally assisted cracking of reactor materials using pneumatic servo-controlled fracture mechanics device, Int. J. Pres. Ves. Pip. 83 (2006) 701-706.

[4] A.K. Jha, V. Diwaker and K. Sreekumar, Metallurgical investigation on stainless steel bellows used in satellite launch vehicle, Eng. Fail. Anal. 13 (2006) 1437-1447.

[5] A. Imazu, K. Iwata, Y.Wada and T. Nagata, Recent achievements at PNC in the development of high temperature structural design methods for FBR components, Nucl. Eng. Des. 138 (1992) 269-282.

[6] J.A. Brown and G.A. Tice, Containment penetrations - flexible metallic bellows: testing safety, life extension issues, Nucl. Eng. Des. 145 (1993) 419-430.

[7] M. Matula, L. Hyspecka, M. Svoboda, V. Vodarek, C. Dagbert, J. Galland, Z. Stonawska and L. Tuma, Intergranular corrosion of AISI 316L steel, Mater. Charact. 46 (2001) 203-210.

[8] H. M. Shalaby, Failure investigation of a convection line elbow, Eng. Fail. Anal. 14 (2007) 739-742.

[9] O. M. Alyousif and R. Nishimura, The stress corrosion cracking behaviour of austenitic stainless steels in boiling magnesium chloride solutions, Corros. Sci. 49 (2007) 3040-3051.

[10] S. Ghosh and V. Kain, Microstructural changes in AISI 304L stainless steel due to surface machining: effect on its susceptibility to chloride stress corrosion cracking, J. Nucl. Mater. 403 (2010) 62-67.

[11] L. Zhang, B. An, S. Fukuyama, T. Iijima and K. Yokogawa, Characterization of hydrogen-induced crack initiation in metastable 
austenitic stainless steels during deformation, J. Appl. Phys. 108 (2010) art. no. 063526.

[12] M. Sitko and B. Skoczen, Effect of $\gamma$-a phase transformation on plastic adaptation to cyclic loads at cryogenic temperatures, Int. J. Solids Struct. 49 (2012) 613-634.

[13] M. Hamada, Y. Inoue, T. Nakatani, M. Morishii, Design diagrams and formulae for U-shaped bellows, Int. J. of Pres. Ves. Pip. 4 (1976) 315328.

[14] N. W. Snedden, Analysis and design guidance for the lateral stiffness of bellows expansion joints. Thin wall struct. 3 (1985) 145-162.

[15] G. Subramanian and C. Raghunandan, On improving the fatigue life of U-formed bellows, J. Mater. Process. Tech. 41 (1994) 105-114. 